\title{
El sexto socio del MERCOSUR: Un estudio sobre la penetración importadora china y su impacto en el comercio intrarregional
}

MERCOSUR sixth partner:A study of China's imports policy and its impact on intra regional trade

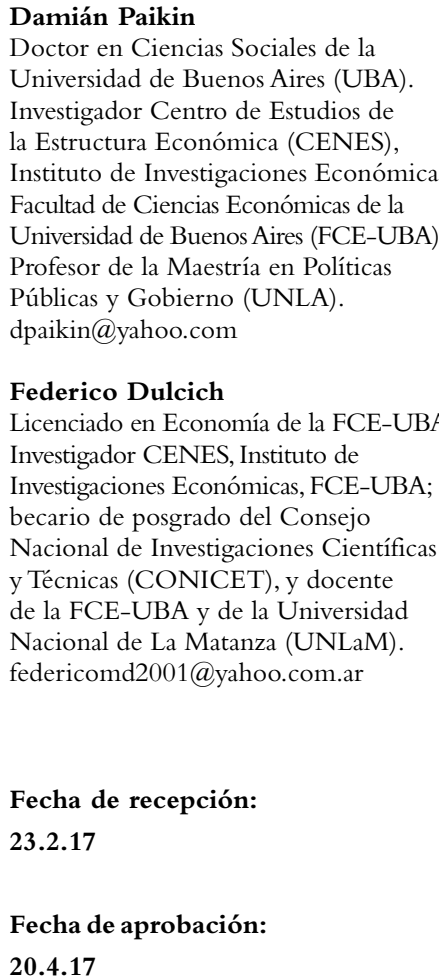

Resumen

El presente artículo busca analizar el intercambio comercial argentino -brasileño de los últimos años y la penetración china en la región con el fin de observar las perspectivas futuras del MERCOSUR y las necesarias opciones de políticas públicas en materia de inserción internacional; se detiene en el análisis sectorial del comercio bilateral y los grados de desplazamiento de la producción regional por proveedores asiáticos encontrando una caída en los últimos años en la participación de las exportaciones argentinas a Brasil y viceversa, al tiempo que se observa un aumento de la participación china en todos los sectores, a excepción del automotriz. Ante esto surgen las preguntas: ¿Es la mayor liberalización y la flexibilización del MERCOSUR, la salida para la economía argentina? ¿Será posible por este camino recuperar mercados en retroceso como el brasileño? O, por el contrario, ¿la mayor regulación regional, como en el caso automotriz, es la base para el sostenimiento de un proceso de desarrollo sostenible? 
Palabras clave: Mercosur - China - sustitución de importaciones - desarrollo - comercio extra regional.

\section{Abstract}

This article analyzes recent years of Argentine-Brazilian commercial exchange and the Chinese penetration in the region in order to observe future prospects of MERCOSUR and what are the public policies options in terms of international insertion. Particularly, the work goes into detail about the sectorial analysis of bilateral trade and the degrees of displacement of regional production by Asian suppliers. We found, in the last years, a decline of Argentina's exports to Brazil and vice versa and an increase of Chinese participation in all sectors, except for the automotive industry. From these facts, some questions arise: More liberalization and flexibility of MERCOSUR is the solution for the Argentina's economy? In doing so will it be possible to recover declining markets, such as the Brazilian one? Or, on the contrary, a greater regional regulation, as in the automotive sector, is the basis for a sustainable development?

Key-words: Mercosur - China - import substitution development - extra- regional trade

\section{Introducción}

El año 2016, primero del nuevo gobierno del presidente Mauricio Macri, transcurrió a la espera de un repunte de la economía que finalmente no sucedió. Entre las razones de esta mala predicción se planteó con justa razón lo sucedido en Brasil, donde su economía no logró frenar su caída más allá de los augurios de numerosos analistas que entendían que la salida de la presidente Dilma Rousseff generaría un cambio en el ciclo recesivo.

De hecho, en numerosas ocasiones, el presidente Macri se refirió a esta situación confiando en una pronta recuperación que apoye a la economía nacional. Así se expresó en junio, por ejemplo, en una reunión previa a la cumbre de la Alianza del Pacífico en Chile, donde manifestó "Esperemos que en los próximos meses Brasil salga de la crisis para que nos beneficie a nosotros también". ${ }^{1}$
Este enfoque, que coloca a Brasil como un eje central de la potencial recuperación de la economía argentina cuenta con numerosas bases sobre los que asentarse. Principal socio estratégico en la región, y probablemente a nivel global, Brasil es además desde la constitución del MERCOSUR el principal destino de las exportaciones argentinas; tomando para sí, en el mejor momento de esta relación, cerca del 30 \% de las mismas.

Pero no sólo en términos cuantificables la importancia de Brasil es central, sino que además en términos de calidad del comercio, nuestros envíos al país vecino cuentan principalmente con manufacturas de origen industrial, donde destaca sin lugar a dudas el intercambio automotriz tanto a nivel intraindustrial como de productos terminados; en un comercio regulado regido por los acuerdos propios del sector dentro del MERCOSUR.

Por todo ello, la esperanza en la recuperación del gigante sudamericano como apuntalador del crecimiento argentino es acertada. Sin embargo, vale la pena relativizar el optimismo en al menos dos dimensiones.

La primera, ¿será el año 2017 el de repunte de la economía brasileña? Y la segunda, y central para este artículo, en caso de que así sea, en qué medida la Argentina recuperará sus espacios de mercado y en que espacios será reemplazado por otros proveedores, particularmente por China.

En este sentido, el presente artículo busca analizar el impacto de la inserción de China tanto en la economía argentina como en la brasileña y los sectores donde los productos provenientes del gigante asiático ya han comenzado hoy a generar procesos de desplazamiento con el fin de poder cuantificar los efectos de una recuperación económica brasileña para la Argentina.

\section{Los últimos cinco años del comercio argentino - brasileño.} Déficit comercial y caída de volúmenes.

Desde el año 1991, con la firma del Tratado de Asunción, y particularmente a partir del año 1995 con la puesta en marcha final de la zona de libre comercio, Brasil fue ganando progresivamente su lugar como principal socio comercial argentino. Así, el MERCOSUR (donde Brasil es el 75\% de las exportaciones y el 90\% de las importaciones argentinas) fue creciendo en importancia, superando a la Unión Europea como principal destino comercial llegando para el año 2000 a explicar el 30,9\% de las exportaciones.

Sin embargo, a partir de ese momento, su importancia comenzó a decrecer, sin por ello perder su lugar de privilegio. La mayor diversificación de los destinos implicó que para el 2016, el MERCOSUR sólo recibiera el 20,3\% de las exportaciones argentinas. Esta baja no redundó por otro lado en un crecimiento de los destinos tradicionales (Europa 
y EEUU), sino que fue reemplazado en gran medida por China, país que entre el año 2000 y el 2015 duplicó su participación porcentual como destino, y otros mercados emergentes como el este asiático y Rusia.

En términos de importaciones, por su lado, el MERCOSUR también se ubica como el principal oferente de productos extranjeros a la Argentina, reduciendo aquí su participación entre el año 2010 y el 2016 del 31,6 al 26,4\%, mientras la participación China crece desde el 14,4 al 18,8\% en los mismos años.

\section{Gráfico 1. Principales socios comerciales argentinos 1990-2016}

\section{(en porcentajes)}

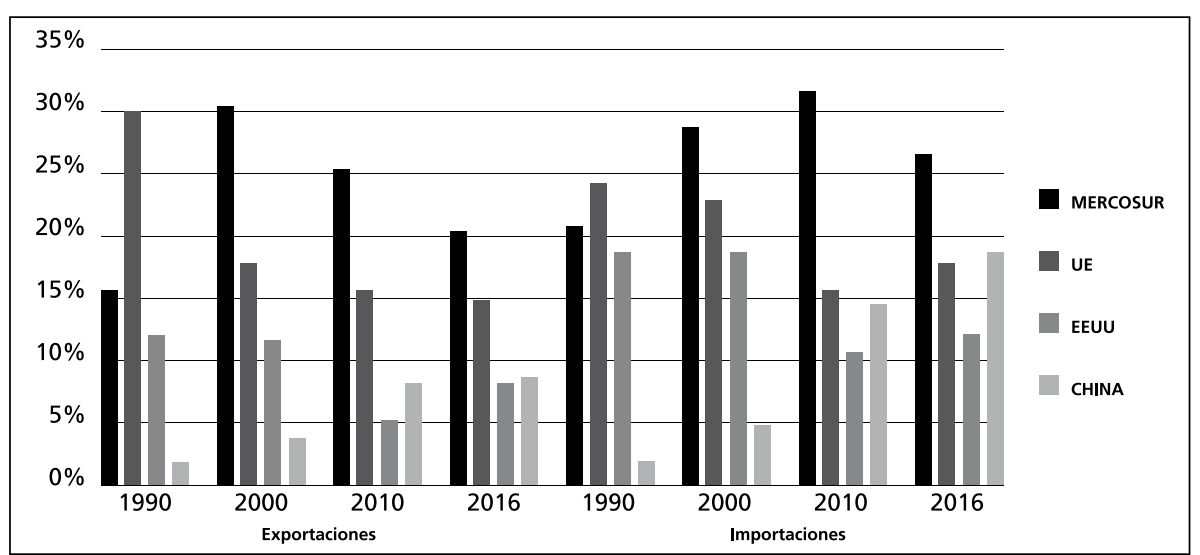

Fuente: Centro de Estudios Internacionales e INDEC.

Es decir, que el MERCOSUR sigue ocupando un lugar de preeminencia en el contexto del comercio exterior argentino; aunque con una tendencia declinante, perdiendo espacio relativo frente al avance de China, particularmente en el terreno de las importaciones, donde el gigante asiático viene reemplazando, entre otros, al socio sudamericano. Para el caso de Brasil, por su parte, el MER COSUR (y Argentina particularmente que explica el $75 \%$ de ese comercio) nunca logró posicionarse como el primer socio comercial, alternando entre el tercer y cuarto lugar, teniendo su mejor desempeño a fines de los '90 y principios de los 2000 donde explicaba alrededor del 15\% del comercio exterior brasilero, hasta el cerca del 10\% actual.
Gráfico 2. Principales socios comerciales brasileños 1990-2016 (en porcentajes)

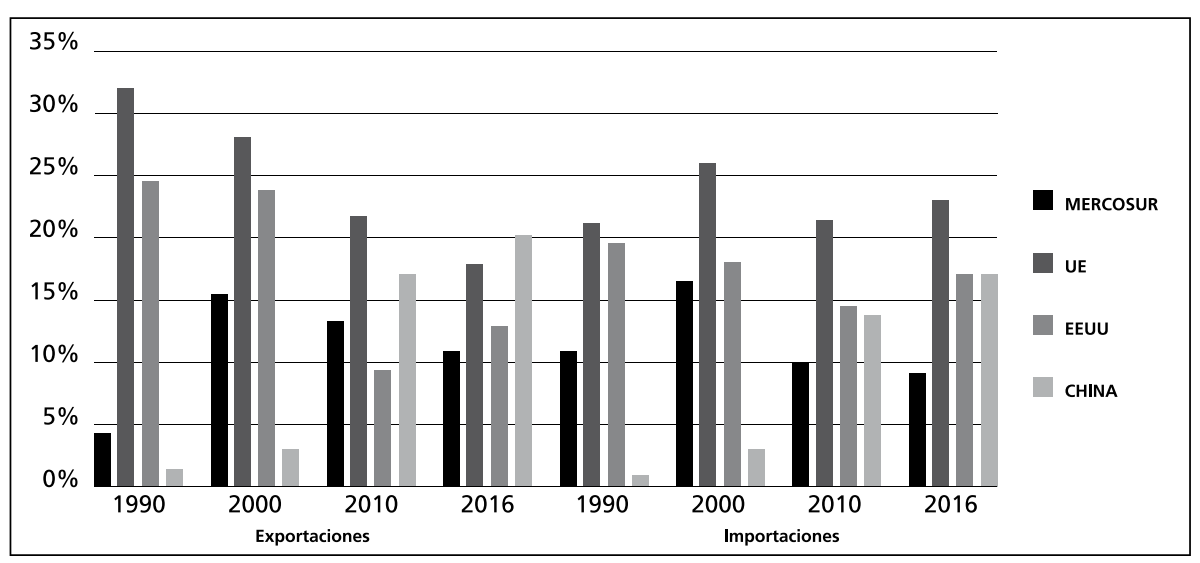

Fuente: Ministerio de Industria, Comercio Exterior y Servicios (Brasil).

En particular,la incidencia de China sobre Brasil es aún mayor que sobre Argentina, siendo ya el principal socio comercial en materia de exportaciones y el segundo en términos de importaciones, dejando sin embargo una particularidad donde el MERCOSUR cobra valor. Así como para la Argentina, China implica para Brasil una fuerte primarización de sus exportaciones donde a la soja se le suma con mucha fuerza el mineral de hierro que explica el $35 \%$ de ese comercio. ${ }^{2}$

En este contexto global, los últimos años del comercio intramercosur, pese a mantener su complementariedad intra-industrial y su sesgo manufacturero, pueden definirse como inmerso en un flujo decreciente; particularmente afectado por la crisis brasileña. 


\section{Tabla 1. estructura de las exportaciones argentinas (en \%)}

\begin{tabular}{|c|c|c|c|c|}
\cline { 2 - 5 } \multicolumn{1}{c|}{} & \multicolumn{4}{|c|}{ Exportaciones al Mundo } \\
\cline { 2 - 5 } \multicolumn{1}{c|}{} & PP & MOA & MOI & RESTO \\
\hline $\mathbf{1 9 9 5}$ & 23 & 35,6 & 31 & 10,4 \\
\hline $\mathbf{2 0 0 0}$ & 20,3 & 29,9 & 32,2 & 18,6 \\
\hline $\mathbf{2 0 0 5}$ & 20,1 & 32,5 & 29,7 & 17,7 \\
\hline $\mathbf{2 0 1 0}$ & 22 & 33,5 & 35,1 & 9,4 \\
\hline $\mathbf{2 0 1 5}$ & 23,5 & 41 & 32 & 3,5 \\
\hline
\end{tabular}

\begin{tabular}{|c|c|c|c|}
\hline \multicolumn{4}{|c|}{ Exportaciones al MERCOSUR } \\
\hline PP & MOA & MOI & RESTO \\
\hline 21,1 & 18,2 & 46,8 & 14 \\
\hline 16,5 & 13,5 & 48 & 22 \\
\hline 13,8 & 11,6 & 58,4 & 16,1 \\
\hline 10,3 & 11,7 & 68,6 & 9,4 \\
\hline 11.3 & 12 & 62,4 & 14,3 \\
\hline
\end{tabular}

Fuente: Elaboración propia a partir de datos del EI/Cancillería.

Desde 2010 la economía brasileña muestra signos de decaimiento que se convirtieron en recesión en el último año, con una caída en 2015 del 3,8\%, del 3,5 en 2016 y de 0,5 proyectada en 2017,3 con la consecuente retracción de su capacidad de absorción de las exportaciones argentinas (gráfico $\mathrm{N}^{\circ} 3$ ). Esto se complementa al sinuoso camino de las importaciones, donde el achicamiento de la economía argentina en 2013 sumado a las políticas de regulación del mercado de divisas generaron un retraimiento que aplacó el déficit comercial durante dicho año y 2014. Déficit que se volvió a ampliar en 2015 de cara al nuevo crecimiento de la economía argentina e incluso en el 2016, en el marco de un nuevo estancamiento económico pero con liberalización comercial y fronteras abiertas.

\section{Gráfico 3. Flujos comerciales de Argentina con Brasil.}

\section{Período 2011-2016 (en dólares)}

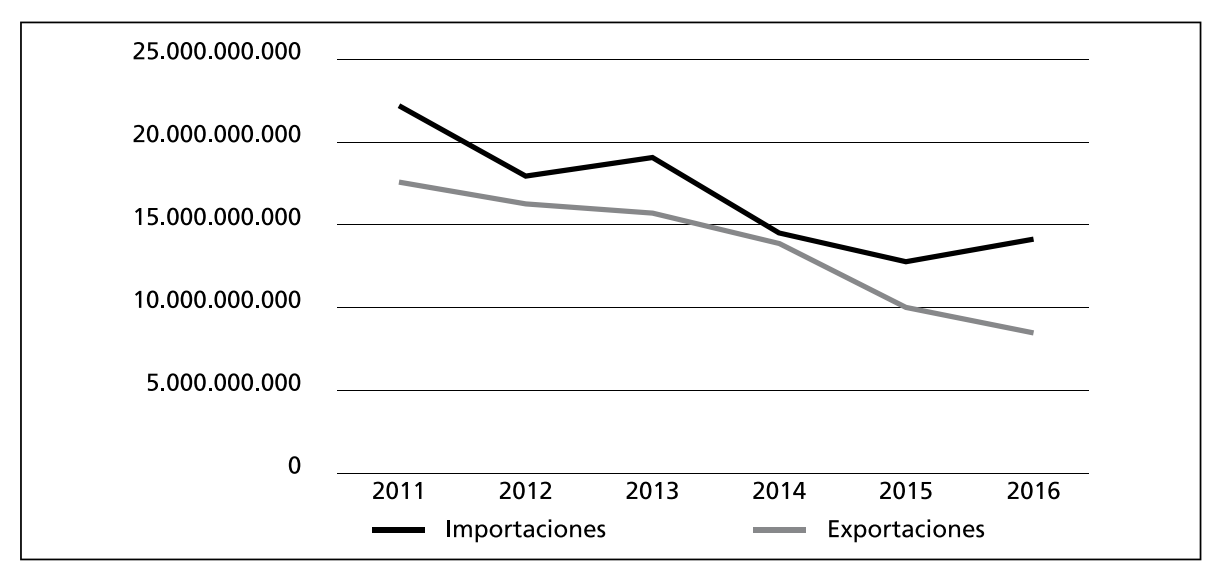

Por tanto, lo que se ha observado en estos últimos cinco años es el decaimiento de un comercio bilateral que supo ser central y provechoso principalmente para la Argentina, pero también para los sectores industriales de Brasil y sobre el cual se depositan fuertes esperanzas en su recuperación.

Sin embargo, como se ha dicho al comienzo, la esperanza debe ser en parte relativizada, ya que mientras este comercio regional se retrajo, otros actores, y particularmente China fueron ganando mercado tanto en las importaciones brasileñas como argentinas, reemplazando justamente, y principalmente, a los proveedores regionales.

En este sentido, es menester analizar sectorialmente cual ha sido este derrotero y en función de ello repensar estrategias posibles para fortalecer el MERCOSUR y sus marcos regulatorios para que dicha esperanza, en caso de que llegue la recuperación económica, tenga bases solidas sobre las cuáles fundarse.

\section{China como reemplazo de las importaciones}

en Argentina y Brasil: un análisis sectorial.

Como se ha dicho anteriormente, en los últimos quince años la presencia China en América del Sur ha crecido notablemente. De una posición marginal en donde se encontraba en el año 2000, paso a colocarse como el principal destino de las exportaciones brasileñas y, si se toma en cuenta a la Unión Europea en su conjunto, en el segundo proveedor de importaciones tanto para la Argentina como para Brasil; dentro de un fenómeno global de crecimiento de la influencia de los intercambios comerciales con el continente asiático de largo plazo, asociado a su industrialización y demanda de bienes primarios (Dulcich, 2015).

Por lógica, este crecimiento se construyó a partir de dos fenómenos. Creación de nuevos flujos comerciales, en el marco de la ampliación de las economías y de sus importaciones y, por otro lado, reemplazo de flujos existentes tomando para sí cuotas del mercado que se encontraban en manos de proveedores de otros países.

En el caso que nos ocupa, las relaciones argentino-brasileñas, se puede afirmar que antes que creación de mercado, el crecimiento chino se ha dado principalmente mediante el reemplazo de proveedores, sobre todo en los últimos años de estancamiento económico de la región. Este dato es sencillo de ser comprobado al apreciar que pese al retroceso global de las importaciones en ambos países, la participación china sobre las mismas aumenta. El único caso contrastante es el del año 2016 en la Argentina, donde hay un leve retroceso de las importaciones chinas y un aumento de las brasileñas, explicado sobre todo por el crecimiento de la venta de automóviles $0 \mathrm{~km}$. 
Gráfico 4. Participación de las importaciones chinas en Argentina (2013-2016)

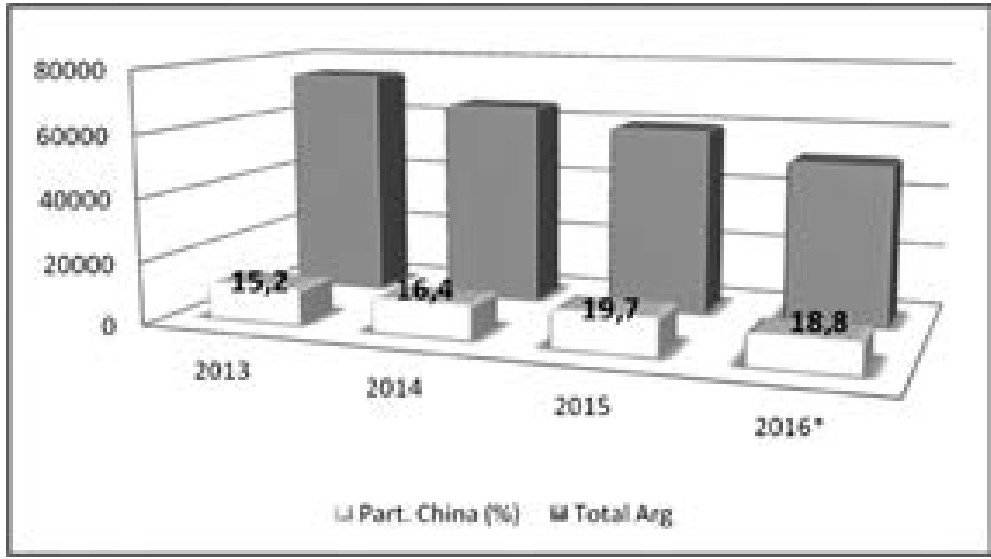

Fuente: INDEC.

(*) Hasta Noviembre.

Gráfico 5. Participación de las importaciones chinas en Brasil (2013-2016)

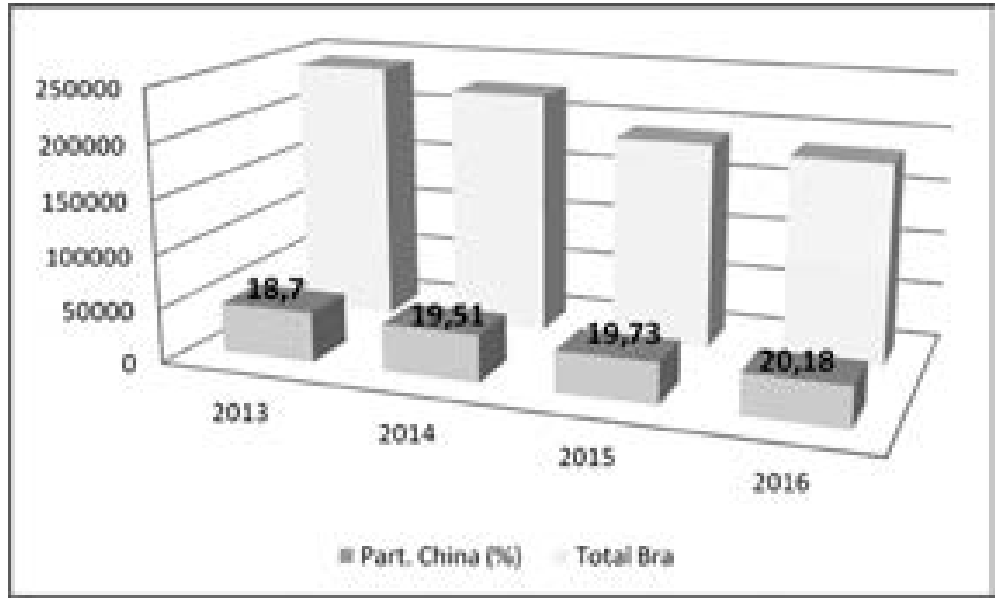

Fuente: Ministerio de Industria, Comercio Exterior y Servicios (Brasil)
El avance de la participación china, entonces, se da tomando porciones de mercado, tanto de proveedores regionales como extra regionales. Dado nuestro interés, evaluaremos en qué medida este reemplazo se dio en principio sobre las exportaciones argentinas a Brasil y viceversa.

Para ello tomaremos dos períodos de tiempo. El primero (2002-2004) representa el momento de inicio, cuando la presencia China aún era marginal.Vale recordar que recién en el año 2001 el gigante asiático fue aceptado como miembro de la Organización Mundia de Comercio (OMC), lapso a partir del cual debió recorrer un período de 15 años de transición para estar en condiciones de ser aceptado como economía de mercado.

El segundo, es el actual en virtud de los datos con los que contamos, es decir el promedio entre los años 2013-2015. La utilización de un promedio de tres años obedece a buscar evitar los sesgos de los movimientos coyunturales que pudieran haber sucedido en dichos períodos.

Finalmente, se lista de arriba a abajo según la importancia de cada sector en relación al momento de arranque, dejando sentado que los sectores analizados implican más del $80 \%$ del flujo exportador.

Tabla 2. Participación Argentina y China en importaciones Brasileñas

\begin{tabular}{|c|c|c|c|c|c|c|c|}
\hline \multirow[b]{2}{*}{ Descripción Sector } & \multirow{2}{*}{\begin{tabular}{|l} 
Importaciones de Brasil \\
desde Argentina Prom. \\
2002-2004 (Mill USS)
\end{tabular}} & \multicolumn{3}{|c|}{ Part.Argentina } & \multicolumn{3}{|c|}{ Part. China } \\
\hline & & $\begin{array}{c}\text { Prom. } \\
\text { 2002-2004 }\end{array}$ & $\begin{array}{c}\text { Prom. } \\
\text { 2013-2015 }\end{array}$ & 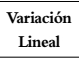 & $\begin{array}{c}\begin{array}{c}\text { Prom. } \\
\text { 2002-2004 }\end{array} \\
\end{array}$ & \begin{tabular}{|c|c|} 
Prom. \\
2013-2015
\end{tabular} & $\begin{array}{c}\text { Variacíó } \\
\text { Lineal } \\
\end{array}$ \\
\hline Total & 4.995 & $10 \%$ & $6 \%$ & $-4 \%$ & $6 \%$ & $18 \%$ & $12 \%$ \\
\hline $\begin{array}{l}\text { Combustibles y aceites minerales, } \\
\text { y productos de su destilación }\end{array}$ & 930 & $11 \%$ & $2 \%$ & $-9 \%$ & $6 \%$ & $0 \%$ & $3 \%$ \\
\hline Cereales & 844 & $71 \%$ & $43 \%$ & $-29 \%$ & $0 \%$ & $0 \%$ & $0 \%$ \\
\hline $\begin{array}{l}\text { lehículos automóviles, tractores, } \\
\text { velocípedos y demás vehículos }\end{array}$ & 742 & $27 \%$ & $34 \%$ & $8 \%$ & $1 \%$ & $5 \%$ & $4 \%$ \\
\hline Plásticos y manufacturas & 388 & $19 \%$ & $8 \%$ & $-11 \%$ & $1 \%$ & $12 \%$ & $11 \%$ \\
\hline $\begin{array}{l}\text { Maquinaria y aparatos mecánicos; } \\
\text { sus partes }\end{array}$ & 242 & $3 \%$ & $2 \%$ & $-1 \%$ & $3 \%$ & $22 \%$ & $19 \%$ \\
\hline Productos químicos diversos & 131 & $12 \%$ & $7 \%$ & $-5 \%$ & $1 \%$ & $6 \%$ & $5 \%$ \\
\hline Químicos orgánicos & 126 & $4 \%$ & $1 \%$ & $-3 \%$ & $7 \%$ & $21 \%$ & $14 \%$ \\
\hline Vegetales comestibles, raíces y tubérculos & 107 & $68 \%$ & $37 \%$ & $-31 \%$ & $10 \%$ & $39 \%$ & $29 \%$ \\
\hline Lácteos, huevos de las aves, miel natural & 77 & $49 \%$ & $46 \%$ & $-3 \%$ & $0 \%$ & $0 \%$ & $0 \%$ \\
\hline Productos industriales de la molienda & 69 & $34 \%$ & $50 \%$ & $16 \%$ & $0 \%$ & $1 \%$ & $1 \%$ \\
\hline Productos químicos inorgánicos & 67 & $9 \%$ & $5 \%$ & $-4 \%$ & $7 \%$ & $15 \%$ & $8 \%$ \\
\hline Hierro y acero & 65 & $16 \%$ & $4 \%$ & $-8 \%$ & $3 \%$ & $36 \%$ & $33 \%$ \\
\hline $\begin{array}{l}\text { Pescados y crustáceos, moluscos } \\
\text { y demás invertebrados acuáticos }\end{array}$ & 46 & $22 \%$ & $8 \%$ & $-16 \%$ & $0 \%$ & $18 \%$ & $18 \%$ \\
\hline $\begin{array}{l}\text { Madera y manufacturas de madera, } \\
\text { y carbón de leña }\end{array}$ & 36 & $60 \%$ & $13 \%$ & $-47 \%$ & $3 \%$ & $29 \%$ & $26 \%$ \\
\hline $\begin{array}{l}\text { Aceites esenciales, productos } \\
\text { de perfumería o de tocador }\end{array}$ & 30 & $16 \%$ & $29 \%$ & $13 \%$ & $1 \%$ & $3 \%$ & $2 \%$ \\
\hline $\begin{array}{l}\text { Tejidos impregnados, recubiertos, } \\
\text { revestidos o estratificados }\end{array}$ & 21 & $19 \%$ & 1 & $-18 \%$ & $4 \%$ & $32 \%$ & $28 \%$ \\
\hline Tejidos especiales & 3 & $17 \%$ & $1 \%$ & $-16 \%$ & $12 \%$ & $73 \%$ & $61 \%$ \\
\hline
\end{tabular}

Fuente: Elaboración propia en base de datos de UN Comtrade. 
En la Tabla 2 se muestra, al lado de cada sector, el porcentaje de la participación argentina en las importaciones brasileñas, tanto en el momento de inicio como el actual, expresando asimismo la variación entre ambos períodos. A continuación, se realiza la misma aproximación para el caso de la participación de China.

Para facilitar la lectura, en gris claro se ha remarcado aquellos sectores donde la variación entre ambos períodos fue negativa, mientras en gris oscuro se resalta el fenómeno opuesto, o sea el aumento de la participación en estos años.

Tomando en cuenta estos parámetros, se pueden ir analizando a partir de la lectura de los datos diferentes cuestiones. La primera, y más notable, es que la Argentina muestra un retroceso general de su participación en las importaciones brasileñas en los últimos quince años en todos los sectores, a excepción de vehículos, productos de la industria de la molienda y productos de tocador donde crece 8,16 , y 13 puntos porcentuales, respectivamente.

Por el contrario, el crecimiento de la participación china es casi tan general como la caída argentina, generándose en muchos sectores un reemplazo casi de la misma dimensión. Este comportamiento se puede observar particularmente en cuatro sectores, dos de ellos industriales y sumamente representativos en el total de las importaciones, como son los plásticos y químicos; y dos manufacturas de origen agropecuario (incluyendo la pesca), como son los vegetales, ya que se trata de productos congelados, enlatados y preservados, y pescados y moluscos, donde la Argentina retrocede en la misma proporción que avanza China.

Por caso, en vegetales preservados para 2002, la Argentina realizaba el $69 \%$ de los envíos, mientras que China no participaba del mercado. En 2014, China ocupó el 54\% y la Argentina fue la que abandonó sus envíos. En filet de pescado, por su parte, el recorrido fue similar. Para 2002, el mercado estaba dividido, con primacía argentina con un $27 \%$ sobre un $21 \%$ chino. En 2014, los asiáticos habían llegado al 74\%, mientras la Argentina no superó el 1\%. ${ }^{4}$

Finalmente, el sector tejidos también sufre una fuerte retracción que lo deja prácticamente fuera del mercado brasileño siendo aquí el crecimiento chino superior al declive argentino con lo cual su avance se da también sobre otros proveedores externos y, asimismo, sobre la industria doméstica, ya que las importaciones textiles crecieron durante el período en promedio un $20 \%$ por año, muy por encima incluso del promedio general que da un $10 \%$ de crecimiento de las importaciones, más allá del declive del último lustro.

Solo en cuatro sectores (Cereales, Lácteos y Miel, Preparaciones de Pieles y Cueros y, finalmente, productos de Panadería) la caída argentina no es compensada en nada por el aumento chino. Son por el contrario, reemplazados por proveedores regionales, particularmente Uruguay y Bolivia, o los Estados Unidos para el caso de la miel, por ejemplo. ${ }^{5}$ Es decir, que en términos de tendencias, los últimos 15 años han visto una caída de la participación argentina en las importaciones brasileñas y un aumento de la importancia china, observándose en ocasiones un reemplazo directo entre ambos y, en otros, un reemplazo a los envíos argentinos por otros proveedores, particularmente en aquellos sectores asociados a las materias primas agropecuarias.

En medio de este panorama negativo, y en contraste con todo lo anterior, el sector automotriz mantiene su vitalidad. Más allá del crecimiento chino, las automotrices argentinas logran ampliar su participación en un mercado difícil apoyado en los acuerdos regulatorios del MERCOSUR y las lógicas de producción de las terminales que tras años de integración piensan la región como un mercado ampliado definiendo sus planes de negocio en virtud de las regulaciones supraestatales.

\section{La situación de las importaciones brasileñas en Argentina}

En el análisis de las importaciones brasileñas a la Argentina, se observa un esquema de la relación con China similar al resaltado para el proceso inverso. De hecho, es aún más importante la transición a nivel sectorial aunque aún Brasil siga siendo el principal importador a la Argentina.

\section{Tabla 3. Participación brasileña y china en importaciones argentinas}

\begin{tabular}{|c|c|c|c|c|c|c|c|}
\hline \multirow[b]{2}{*}{ Descripción del Sector } & \multirow{2}{*}{$\begin{array}{l}\text { Importaciones de Brasil } \\
\text { desde Argentina Prom. } \\
\text { 2002-2004 (Mill USS) }\end{array}$} & \multicolumn{3}{|c|}{ Part. Argentina } & \multicolumn{3}{|c|}{ Part. China } \\
\hline & & \begin{tabular}{|c|}
$\begin{array}{c}\text { Prom. } \\
\text { 2002-2004 }\end{array}$ \\
\end{tabular} & \begin{tabular}{|c|c|} 
Prom. \\
2013-2015
\end{tabular} & $\begin{array}{c}\text { Variación } \\
\text { Lineal }\end{array}$ & \begin{tabular}{|c|c|} 
Prom. \\
2002-2004
\end{tabular} & \begin{tabular}{|c|} 
Prom. \\
$2013-2015$
\end{tabular} & $\begin{array}{c}\text { Variación } \\
\text { Lineal }\end{array}$ \\
\hline Total & 4.297 & $33 \%$ & $23 \%$ & $-10 \%$ & $5 \%$ & $17 \%$ & $12 \%$ \\
\hline Vehículos automóviles, tractores & 1118 & $63 \%$ & $62 \%$ & $-1 \%$ & $1 \%$ & $5 \%$ & $4 \%$ \\
\hline $\begin{array}{l}\text { Maquinarias y aparatos mecánicos; } \\
\text { sus partes }\end{array}$ & 577 & $24 \%$ & $15 \%$ & $-8 \%$ & $8 \%$ & $24 \%$ & $16 \%$ \\
\hline $\begin{array}{l}\text { Maquinaria y equipo eléctrico } \\
\text { y sus partes }\end{array}$ & 346 & $24 \%$ & $9 \%$ & $-15 \%$ & $12 \%$ & $49 \%$ & $7 \%$ \\
\hline Plásticos y sus manufacturas & 337 & $39 \%$ & $30 \%$ & $-10 \%$ & $2 \%$ & $11 \%$ & $8 \%$ \\
\hline \begin{tabular}{|l} 
Químicos orgán \\
\end{tabular} & 270 & $21 \%$ & $11 \%$ & $-10 \%$ & $11 \%$ & $30 \%$ & $19 \%$ \\
\hline Product & & $50 \%$ & $39 \%$ & $-11 \%$ & $7 \%$ & $13 \%$ & $6 \%$ \\
\hline \begin{tabular}{|l|} 
Cauchó : \\
Algodón \\
\end{tabular} & $\frac{141}{107}$ & $\frac{80 \%}{88 \%}$ & $38 \%$ & $-2 \%$ & $4 \%$ & $\frac{8 \%}{25 \%}$ & $\frac{4 \%}{25 \%}$ \\
\hline Productos químicos diversos & 102 & $25 \%$ & $17 \%$ & $-8 \%$ & $2 \%$ & $13 \%$ & $11 \%$ \\
\hline Artículos de fundición, de hierro & 78 & $30 \%$ & $16 \%$ & $-15 \%$ & $5 \%$ & $19 \%$ & $14 \%$ \\
\hline \begin{tabular}{|l|} 
Calzedo y artículos similares, \\
y sus partes
\end{tabular} & 67 & $75 \%$ & $33 \%$ & $-43 \%$ & $15 \%$ & $32 \%$ & $16 \%$ \\
\hline $\begin{array}{l}\text { Fibras sintéticas o artificiales } \\
\text { discontinuas }\end{array}$ & 50 & $48 \%$ & $14 \%$ & $-34 \%$ & $5 \%$ & $24 \%$ & $19 \%$ \\
\hline \begin{tabular}{|l|} 
Aceites esenciales, productos \\
de perfumerí o de tocador
\end{tabular} & 43 & $40 \%$ & $22 \%$ & $-18 \%$ & $0 \%$ & $1 \%$ & $1 \%$ \\
\hline Carne y & 39 & $82 \%$ & $79 \%$ & $-2 \%$ & $0 \%$ & $0 \%$ & $0 \%$ \\
\hline $\begin{array}{l}\begin{array}{l}\text { Equipo de optica, fotografia, } \\
\text { cinematografia, medición, control, } \\
\text { medicinal, etc. }\end{array} \\
\end{array}$ & 37 & $11 \%$ & $8 \%$ & $-2 \%$ & $6 \%$ & $15 \%$ & $9 \%$ \\
\hline $\begin{array}{l}\text { Combustibles y aceites minerales, } \\
\text { y productos de su destilación }\end{array}$ & 37 & $6 \%$ & $2 \%$ & $-4 \%$ & $2 \%$ & $0 \%$ & $-2 \%$ \\
\hline \begin{tabular}{|l|} 
Jabón y otr \\
a
\end{tabular} & 36 & $29 \%$ & $31 \%$ & $2 \%$ & $0 \%$ & $3 \%$ & $2 \%$ \\
\hline Alumi & 36 & $46 \%$ & $35 \%$ & $-11 \%$ & $1 \%$ & $16 \%$ & $15 \%$ \\
\hline $\begin{array}{l}\begin{array}{l}\text { Productos fotográico. } \\
\text { cinematográficos }\end{array} \\
\end{array}$ & 34 & $41 \%$ & $15 \%$ & $-26 \%$ & $0 \%$ & $11 \%$ & 119 \\
\hline
\end{tabular}

Fuente: Elaboración propia en base de datos de UN Comtrade. 
En este caso, todos los sectores analizados, a excepción del jabón, muestran una retracción del peso de las importaciones brasileñas, en algunos casos con magnitudes muy pronunciadas como algodón (40 puntos porcentuales), calzados (43 p.p.) o fibras sintéticas (34 p.p.). Por el contrario, el avance de China es notorio, destacándose en sectores vinculados a los bienes de capital como maquinaria y equipo eléctrico (37 p.p.) y maquinaria y equipos mecánicos (16 p.p.), donde su avance más que compensa el retroceso brasileño, el cual de todas formas es importante y afecta fuertemente la capacidad exportadora de Brasil de bienes de alto valor agregado y fuerte componente tecnológico.

Teniendo estos números en mente, vale la pena aquí hacer un punto. En un estudio anterior realizado por Bekerman, Dulcich y Moncaut (2014), donde se tomaba como punto de análisis los años 2008-2010 se hacía mención al hecho que pese al avance chino, la industria brasileña había sostenido y ampliado su participación en el mercado argentino justamente en los sectores comentados anteriormente (Equipos electrónicos y mecánicos).

Expresamente, se planteaba en el trabajo citado:

El caso de Brasil se presenta contrapuesto al de la Unión Europea (UE) y los Estados Unidos (EU). Su participación en el mercado de importación de maquinaria eléctrica y mecánica ha crecido (de 13 a 23\%, y de 16 a 22\%, respectivamente). De esta forma se aprecia un proceso de regionalización comercial en sectores de medio y alto contenido tecnológico, que persiste más allá del fuerte crecimiento de China, que afecta principalmente a EU y la UE. (Bekerman, Dulcich y Moncaut, pp. 78).

Ahora bien, contrariando esa afirmación, en este nuevo artículo que toma la fotografia cinco años después a la citada, se observa una caída en la participación brasileña en equipos electrónicos del 24 al 9\% y en mecánicos del 24 al 15\%, mientras se comprueba un crecimiento sustancial de la participación china.

¿Qué fue lo que paso? ¿Qué explica tal dinamismo? Lo que sucedió es que China transformó casi por completo su perfil exportador en los últimos cinco años, avanzando sobre nuevos sectores y poniendo en debate aún con más fuerza los lazos comerciales argentinos brasileños de las últimas tres décadas.

En este punto, es importante plantear el rol creciente de China como proveedor de productos de medio y alto contenido tecnológico, lo que confirma su cambio de perfil productivo que la ha llevado de ser productor de manufacturas mano de obra intensiva a ubicarse como un férreo competidor en el área de las manufacturas tecnológicas.
Tal como afirma Girado (2013:47):

Hace cinco años -2008-, el 45\% de las exportaciones de bienes correspondía a manufacturas intensivas en mano de obra y sólo el 8\% a manufacturas que incluían un proceso intensivo en investigación y desarrollo. Ya en 2011, las primeras descendieron al $27 \%$ del total de exportaciones mientras que las segundas duplicaron su presencia hasta el $16 \%$, en un claro progreso de escalamiento tecnológico.

A lo que agrega:

El futuro de las exportaciones de China parece que va a estar encabezado por los productores de equipos, $y$ aunque las empresas chinas todavía no pueden penetrar en los mercados occidentales, la competencia la dan en terceros mercados" (50).

En este sentido el reemplazo del rol de las empresas brasileñas de bienes de capital en la provisión de maquinarías a la Argentina no hace más que reafirmar esta sentencia. Lo que lleva, por otro lado, a una segunda reflexión donde se plantea la dificultad de sostener el modelo MER COSUR de regionalización comercial tal cual se conoce, al menos a partir de regulaciones generales como es la mera utilización arancelaria.

En definitiva, estas transformaciones que quedan evidenciadas en este estudio muestran, a diferencia del que observa lo sucedido en 2008-2010, que las lógicas regulatorias del MERCOSUR no estaban en los últimos años incentivando el comercio intrarregional y que incluso, del 2008-2010 al 2013-2015 se retrocedió fuertemente en el campo de los sectores de mediano y alto componente tecnológico.

Solamente el sector automotriz, al igual que se mencionó en relación a la participación de las importaciones argentinas en Brasil, sorprendentemente aquel que nunca había ingresado a la lógica del libre comercio regional y se había organizado a partir de un régimen de comercio administrado, logró soportar la presión externa y mantener sus cuotas de mercado.

Esta situación obliga entonces a analizar en detalle las estrategias a seguir en virtud de la importancia que aún tiene este comercio intrarregional, con el objetivo de plantear en qué medida es posible revertir esta tendencia. 


\section{Fortalecer o flexibilizar la integración regional \\ Enseñanzas frente al desafío chino.}

Argentina, a diferencia de otros países de la región, tiene tanto en la opinión pública como en sus decisores políticos un acuerdo importante sobre la necesidad del sostenimiento de la integración, y particularmente de las relaciones con Brasil, para un desarrollo pleno de su economía. Según la encuesta del Consejo Argentino de Relaciones Internacionales del año 2015 sobre política exterior, el 29\% de los líderes de opinión considera a Brasil como el pás con el cuál tener las mayores y más firmes relaciones (llegando a 53\% si se toma la mención a toda latinoamérica, donde obviamente se incluye a Brasil, siendo estas dos las principales menciones). ${ }^{6}$ Por tanto la idea de que política regional es entendida como estratégica parece afirmada, razón que viene a sumarse al diagnóstico comentado a comienzo del trabajo donde queda claro que tanto el gobierno anterior, como el actual de Mauricio Macri, consideran la relación con Brasil como fundamental en su idea de "inserción inteligente” al mundo y eje central para la recuperación económica. ${ }^{7}$ Sin embargo, como se ha descripto, las relaciones comerciales intra-regionales se han venido reduciendo paulatinamente por numerosas razones entre las que se ven, como hemos observado, la creciente importancia de las importaciones chinas.

Frente a esto se observan por parte de los actuales gobiernos de los dos países principales del MERCOSUR (Argentina y Brasil) dos líneas de acción. La primera, se asienta en confiar en que la recuperación de la economía logrará recomponer la fuerza de las relaciones comerciales. Cómo hemos analizado, esta premisa probablemente se vuelva utópica partiendo del análisis de los datos concretos en al menos dos dimensiones. La primera, es que aún en los años previos a la crisis (2010-2011) el fenómeno de reemplazo ya había comenzado, ciertamente con menor fuerza en algunos sectores (como se mencionó en el caso de maquinarías). Es decir que aún sin crisis el fenómeno existe. La segunda, es que el continuo crecimiento del poder exportador de la economía china comenzó a abarcar otros sectores claves del comercio regional con una potencia inusitada volviendo muy dificil revertir esta tendencia instalada.

La segunda línea de acción, por otro lado y en forma complementaria a la anterior, es al tiempo que se espera la recuperación económica del socio, apostar a la flexibilización del MER COSUR a partir de la posibilidad de generar unilateralmente firmas de acuerdos de libre comercio con terceros países a partir de la anulación de la Decisión 32/00 que obliga a la ratificación conjunta de estos instrumentos del comercio internacional. Esta idea, planteada en principio por el entonces Canciller José Serra, fue puesta en evaluación por el gobierno argentino en el marco de su idea de ampliar su mirada sobre la Alianza del Pacífico ${ }^{8}$ y con el posterior anuncio uruguayo de una búsqueda autónoma de un acuerdo de libre comercio con China. ${ }^{9}$
Ciertamente, el triunfo de Donald Trump en las elecciones norteamericanas puso al menos un compás de espera sobre esta estrategia con el fin del Tratado Transpacífico y el reordenamiento de las ideas globales sobre los beneficios del libre comercio. Pero al menos para el caso que nos ocupa, una estrategia flexibilizadora de las normativas regulatorias regionales comunes como el arancel externo plantea un serio interrogante sobre su coherencia con el pretendido auxilio que generaría la aspiradora de exportaciones de un recuperado Brasil.

El MERCOSUR actual parece incapaz de recuperar por la lógica misma del mercado, sin intervención estatal - y aún con ella posiblemente - los niveles del comercio intrarregional de otros tiempos. De hecho, los números de la penetración china presentados se han dado sobre un MERCOSUR "rígido" según la mirada actual. Ante esto surge entonces la pregunta de por qué aquellos valores soñados del $30 \%$ de las exportaciones argentinas a Brasil volverían ante un mercado más abierto del país vecino.Y lo mismo se puede decir sobre las importaciones industriales brasileñas a la Argentina que tan exitosas fueron (y siguen siendo) para amplios sectores de la industria paulista.

Por el contrario, el análisis de los datos muestra que el único sector que se sostuvo a lo largo del tiempo (y de hecho el de mayor importancia en el comercio intrarregional) es el automotriz, donde lo que prima no es el libre comercio sino un régimen especial de comercio regulado.

El Régimen Automotor del MERCOSUR confeccionado en 1995 y con múltiples prorrogas y enmiendas cuenta entre sus pilares, según Baruj y Porta (2005:60):

La administración de una reserva de mercado (a través de importaciones de extrazona a tasas preferenciales) por parte de las empresas terminales instaladas en el país - que luego fue discontinuada- $y$ un programa de intercambio compensado dentro del MERCOSUR, con coeficientes variables de comercio según las diferentes coyunturas atravesadas por Argentina y Brasil. En este sentido, aparece como la única política que, en cierta medida, estimula la complementación productiva intrazona, promoviendo el comercio; al mismo tiempo, que por momentos restringe la libre circulación, regulando la dirección y el contenido de los flujos.

Ciertamente, el sector automotor, dominado por unas pocas terminales a nivel global, no aparece necesariamente como el mejor ejemplo para ampliar al resto de los sectores, mucho más difusos y contradictorios en términos de organización de las cadenas tanto en términos verticales como horizontales, pero al menos parece dar una orientación de por donde se po- 
dría pensar una intervención estatal coordinada que apunte a recuperar espacios de mercado regionales y por tanto rentabilidades y empleos para las naciones involucradas.

De esta forma, los dilemas abiertos para el MERCOSUR, ante la baja efectividad de su estadío "liberal" en esta nueva fase del comercio global (basado principalmente en la liberalización comercial interna y en el arancel externo común) no parecen ubicarse en una mayor apertura unilateral, ni en una reducción de los flujos comerciales intrarregionales, sino por el contrario en una mayor regulación de dicho comercio, con mecanismos compensatorios que permitan mediante criterios negociados un sostenimiento y crecimiento de los intercambios, otorgando ventajas e incentivos para la constitución de cadenas de valor regionales.

La superposición sectorial del Área Aduanera Especial de Tierra del Fuego y de la Zona Franca de Manaos (donde en ambas zonas se producen y venden - o vendían - al mercado interno principalmente productos de electrónica de consumo, sin aprovechar ganancias de escala y especialización, como se aprecia en Bekerman y Dulcich, 2017) dan cuenta de los desafios asociados a esta idea, que actuaron como límite incluso en momentos de alta convergencia ideológica a nivel gubernamental como fueron los de la última década. Por tanto, no es un tarea fácil, pero parece la única viable para sostener grados importantes de autonomía y desarrollo industrial en este nuevo contexto mundial.

\section{Conclusiones}

El presente trabajo ha tenido como objetivo analizar las relaciones comerciales argentino-brasileñas, centrando la atención en la penetración importadora china en la región y su influencia en la reconstitución de dichas relaciones. Se partió de la idea de relativizar la posibilidad de que un repunte en la economía brasileña recomponga a niveles anteriores tanto los montos como especialmente la participación de los envíos argentinos al país vecino, para luego profundizar en torno a una mirada sectorial sobre las formas en que la presencia china ha desplazado o no cadenas de proveedores regionales.

Tanto para el caso de las exportaciones argentinas a Brasil, como en el inverso, la conclusión fue la misma. De quince años a esta parte, en la mayoría de los sectores analizados (los cuales representan más del 80\% del comercio bilateral) la participación de los proveedores regionales ha decrecido, mientras que la de China ha aumentado, encontrando en algunos casos un reemplazo directo y en otros una combinación entre importaciones chinas y de otros países, por un lado, o una penetración china que ha desplazado no sólo a la Argentina en Brasil, sino también a otros países, por el otro.

Incluso, comparando con otros trabajos previos, se nota que este fenómeno se viene profundizando. Así mientras se consignaba que en sectores proveedores de bienes de capital, Brasil había logrado ampliar su participación entre fines de los '90 y los años 2008-2010, esta tendencia se ha revertido totalmente para los años 2013-2015, donde China tomó para sí porciones del mercado argentino desplazando al país vecino y dando cuenta de una nueva búsqueda del país asiático por alcanzar destinos con productos de media u alta dotación de tecnología.

Esta realidad, de pérdida de porciones de mercado en el marco de un decrecimiento general del comercio asociado a las crisis económicas de los países sólo fue contrastada con fuerza en el caso del sector automotriz, donde en base a las regulaciones del sector automotriz del MERCOSUR, el comercio intrarregional se mantuvo en sus valores históricos de participación, más allá de la variaciones coyunturales de los montos.

Datos estos que exponen una cuestión que entendemos precisa ser discutida. La realidad, evidente, es que si se entiende que el vinculo comercial argentino-brasileño es fundamental para ambos países ( $\mathrm{y}$ al menos esto es así en el caso argentino ya que es su principal socio), la inercia de los acuerdos existentes no es suficiente, ya que el proceso de pérdida de participación de los proveedores locales en ambas economías tiende a profundizarse, debilitando la fuerza del comercio intrarregional.

Esto obliga a una redefinición del MERCOSUR, que fue reclamada a los gobiernos de la última década, y también debe ser planteada sobre las nuevas autoridades. Sin embargo, esta nueva etapa de integración debe ser pensada fortaleciendo el MERCOSUR y no flexibilizando sus cimientos.

La flexibilización del MERCOSUR con entrada de nuevos acuerdos comerciales tenderá a debilitar aún más el comercio intrarregional, generando un retroceso aún mayor para la Argentina en virtud de futuras potenciales ganancias en un mundo cada vez más incierto. Por el contrario, un fortalecimiento de las regulaciones aseguraría, como en el caso del sector automotor, porciones de mercado, incentivando a la construcción de cadenas de valor regionales. Posiblemente, como se dijo, el ejemplo sectorial no sea el adecuado para extender por las características del sector, pero si marca un rumbo de la necesidad de pensar políticas coordinadas regionalmente que provean espacios de desarrollo comunes o lógicas de especialización claras.

El MERCOSUR una vez más en crisis, parece de todas formas volver a tener una oportunidad de refundarse, creciendo sobre lo construido. En un mundo cambiante, donde en menos de un año se paso del súmmum del Acuerdo Transpacífico al Brexit, el triunfo de Donald Trump y el replanteo del NAFTA, la región vuelve a demandar su lugar como espacio posible de desarrollo sostenible para nuestros países. Vale la pena volver a discutir esa posibilidad. 
1 El Economista Diario. "Macri confia en la recuperación de Brasil" (1/6/2016). Disponible en http://www leconomista.com.ar/2016-06-macri-confia-en-la-recuperacion-de-brasil (Último acceso 12/01/2016). 2 Más del $70 \%$ de las exportaciones brasileñas a China se ubican en estos dos elementos (Fuente: Comtrade). 3 Fuente: Ministerio de Hacienda de Brasi.

4 Fuente: UN Comtrade.

5 Por ejemplo, en leche líquida en el año 2002, Uruguay concentraba el 62\% de las exportaciones a Brasil, mientras que la Argentina tenía el 36\% del mercado. Para 2014, Uruguay había tomado el 90\%. La Argentina, por su parte, conservaba su preeminencia en leche concentrada con cerca del $75 \%$ de las importaciones 2002, Uruguay concentraba el 62\% de las exportaciones a Brasil, mientras que la Argentina tenía el $36 \%$ del mercado. Para 2014. Uruguay había tomado el 90\%. La Argentina, por su parte, conervaba su preeminenci en leche concentrada con cerca del $75 \%$ de las importaciones brasileñas (Fuente: Atlas de la Complejidad Económica / Harvard university).

6 hlttp://www.cari.org.ar/pdf/encuesta2015.pdt (última visita 13/01/2017).

7 En este sentido, el Ministro de Producción de la Nación, Francisco Cabrera definió en el marco de la reunión entre el presidente Macri y el presidente Temer que: "Estamos avanzando en el fortalecimiento de la agenda bilateral y Brasil es un socio estratégico para que Argentina pueda continuar su camino de desarrollo y lograr una inserción internacional inteligente tanto dentro del Mercosur como con el resto del mundo" (03/10/2016) Disponble en http://www.produccion.gob.ar/argentina-y-brasil-firmaron-acuerdo-para-fortalecer-el-comercio8 Télam. Sección Política "Argentina pidió prudencia ante la propuesta de Brasil de cambiar el modelo del MER COSUR", 27/05/2016. Disponible en /http://www.telam.com.ar/notas/201605/149152-susanamalcorra-cancilleria-argentina-planteo-brasil-mercosur.htm] (último acceso 13/01/2017).

nalcorra-cancilleria-argentina-planteo-brasil-mercosur.htm (ulttimo acceso 13/1918" (19/10/2016) Disponible

en http://www.elpais.com.uy/informacion/uruguay-china-fijaron-fecha-tlc.html (última visita 15/01/2017).

\section{Referencias}

Baruj, G. y Porta, F. (2005) Políticas de competitividad en la Argentina y su impacto en el MERCOSUR. Santiago de Chile, CEPAL, Documento de Proyecto.

Bekerman, M; Dulcich, F. y Moncaut, N. (2014) "La emergencia de China y su impacto en las relaciones comerciales entre Argentina y Brasil", Revista Problemas de Desarrollo 176: págs. 55 - 82.

Bekerman, M; y Dulcich, F. (2014) "Dependencia Comercial y patrones de especialización en un proceso de integración regional. El caso de Argentina y Brasil” en Revista Desarrollo Económico, vol 53, N 211:373-404.

Bekerman, M; y Dulcich, F. (2017) "Políticas productivas en la postconvertibilidad: el caso de Tierra del Fuego y su comparación con la Zona Franca de Manaos de Brasil". Documento de Trabajo del CENES N ${ }^{\circ}$ 24. Instituto de Investigaciones Económicas de la Universidad de Buenos Aires. En prensa.

Bekinschtein, José (2011), “América Latina y China: del Consenso de Washington al precepto de Pekín", en Escenarios alternativos, Buenos Aires, Fundación Centro de Estudios para el Cambio Estructural.

CARI, Consejo Argentino de Relaciones Internacionales (2015) La Opinión Pública Argentina sobre Política Exterior y Defensa. Buenos Aires: CARI.

D’Elía, C. y Berretonni, D. (2013) “El comercio de la Argentina por Regiones 1990 -2011”. Revista Argentina de Economía Internacional, № 1:89-104.

Dulcich, F. (2015) "La Nueva División Internacional del Trabajo y su impacto en el desarrollo económico”. Realidad Económica N 296:113-141.

Girado, G. (2013) "El cambio en el patrón manufacturero chino", Revista Voces del Fénix $N^{\circ} 26$, Revista Digital disponible en http://www.vocesenelfenix.com/content/ el-cambio-en-el-patr\%C3\%B3n-manufacturero-de-china

INDEC, Instituto Nacional de Estadísticas y Censo (2016) Intercambio Comercial 2016. Documento de Información, 22 de Diciembre. 